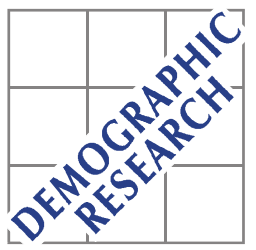

Demographic Research a free, expedited, online journal of peer-reviewed research and commentary in the population sciences published by the Max Planck Institute for Demographic Research Konrad-Zuse Str. 1, D-18057 Rostock · GERMANY www.demographic-research.org

DEMOGRAPHIC RESEARCH

VOLUME 23, ARTICLE 34, PAGES 963-996

PUBLISHED 16 NOVEMBER 2010

http://www.demographic-research.org/Volumes/Vol23/34/

DOI: $10.4054 /$ DemRes.2010.23.34

Research Article

\title{
The implications of marital instability for a woman's fertility: Empirical evidence from Italy
}

Silvia Meggiolaro

Fausta Ongaro

(C)2010 Silvia Meggiolaro \& Fausta Ongaro.

This open-access work is published under the terms of the Creative Commons Attribution NonCommercial License 2.0 Germany, which permits use, reproduction \& distribution in any medium for non-commercial purposes, provided the original author(s) and source are given credit.

See http:// creativecommons.org/licenses/by-nc/2.0/de/ 


\section{Table of Contents}

1 Introduction $\quad 964$

$2 \quad$ Literature and hypotheses 966

2.1 Predictors of childbearing after a marital dissolution: Repartnering 966

and children from the first marriage
2.2 The impact of marital instability on a woman's fertility

3 Data, methods, and measures $\quad 972$

3.1 Data and sub-samples $\quad 972$

3.2 Methods and measures 976

3.2.1 Modelling the predictors of childbearing after marital disruption 976

3.2.2 Modelling the effects of marital dissolution on cumulated fertility 977

$4 \quad$ Analysing the predictors of childbearing after marital disruption $\quad 979$

4.1 A preliminary descriptive analysis $\quad 979$

4.2 Modeling the predictors of childbearing after marital disruption $\quad 981$

$5 \quad$ Analysing the effects of marital dissolution on cumulated fertility 983

5.1 A first look at the differences in fertility between women in $\quad 984$

5.2 Modelling the effect of marital dissolution on cumulated fertility
985

$\begin{array}{lll}6 & \text { Conclusions } & 988\end{array}$

$\begin{array}{ll}\text { References } & 992\end{array}$ 


\title{
The implications of marital instability for a woman's fertility: Empirical evidence from Italy
}

\author{
Silvia Meggiolaro ${ }^{1}$ \\ Fausta Ongaro $^{2}$
}

\begin{abstract}
Using a sample of Italian women interviewed in 2003 in the survey "Family and Social Subject," this paper investigates two issues: (1) how a woman's family life-course (union status and parity/ages of children born in the first marriage) influences the risk of a post-dissolution birth among separated women; and (2) how the experience of a marital disruption affects a woman's cumulated fertility. Given that in Italy marital instability is relatively recent and still barely socially accepted, our main assumption is that separated women engage in more prudent reproductive behaviour than their counterparts living in countries with a longer experience of the phenomenon. With respect to the first point, our results show that: (i) not only remarriage, but also cohabitation, are strongly associated with the likelihood of post-dissolution childbearing; (ii) significant differences in the risk of having a child following the dissolution of a marriage are present only between separated women with no children and separated women with children; thus, separated women with one child have the same probability of experiencing a post-dissolution birth as those with two or more children, and the age of children is irrelevant. With respect to the second point, we find that women who underwent a marital dissolution have lower fertility than those who remained continuously married, and that repartnering enables this group of women to recapture some - but not all — of the fertility lost with the dissolution of the first marriage.
\end{abstract}

\footnotetext{
${ }^{1}$ Department of Statistical Sciences, University of Padova, Via C. Battisti 241, 35121 Padova, Italy. E-mail: meg@stat.unipd.it.

${ }^{2}$ Department of Statistical Sciences, University of Padova, Via C. Battisti 241, 35121 Padova, Italy.

E-mail: ongaro@stat.unipd.it.
} 


\section{Introduction}

Since the numbers of separations and divorces in Europe began to climb in the 1970s, scholars have become increasingly interested in studying the implications of these trends on individuals' fertility. As significant numbers of women and men spend a proportion of their lives in a "post-dissolution" state, important questions arise about their reproductive behaviour. To what extent is marital instability a source of discontinuity of the reproductive career that ultimately reduces the family size of individuals? Which individuals are more likely to have children after marital dissolution? Are there specific circumstances or biographic patterns that may compensate for, or even reverse, the potential negative effects of separation on fertility?

A marital dissolution interrupts the period, which began with marriage, when a woman is at risk of conception, and thus lowers the chances that she will achieve the expected family size. As a consequence, marital instability may, theoretically, be considered a depressing factor for fertility. However, empirical studies have not always supported this hypothesis. Some of them have indeed demonstrated that separation has a negative effect on fertility (Lesthaeghe and Moors 1994; Thomson et al. forthcoming). Other studies have, however, found that, in the case of repartnering, the fertility of separated individuals may be similar to, or only slightly lower than, the fertility of individuals in intact marriages (Jansen, Wijckmans, and Bavel 2008; Beaujouan and Solaz 2008). These findings therefore suggest that the negative effect of exposure to the risk of conception might be overestimated. More recent studies focusing on childbearing patterns among stepfamilies tend to support this hypothesis: they have found that the desire to have shared children with the new partner may lead to a recapturing of most of the "lost children" due to the dissolution of the first marriage (Thomson and Li 2002; Thomson et al. 2002).

This paper aims to examine the relationship between marital instability and fertility, with a focus on the female population. Two specific issues are examined. First, we study the determinants of childbearing following separation among women who experienced a marital dissolution; in this analysis, we are specifically interested in the role played by some family life-course factors connected with the experience of separation (i.e., the children of the first marriage and the partnership trajectory subsequent to the marital disruption). Second, we analyse the overall effect of union dissolution on a woman's cumulated fertility by comparing women in both continuing and interrupted marriages. Our main interest is in assessing to what extent marital instability lowers a woman's fertility, even if she has formed a second union at a fecund age, and to what extent the exposure to the risk of conception plays a role in influencing the woman's fertility overall. 
These two issues are examined for a sample of Italian women interviewed in 2003. Existing studies on the relationship between marital dissolution and fertility are based on US data, or on data from Northern and Central European countries (for a review of previous research, see, for example, Vikat, Thomson, and Hoem 1999). No studies on this topic have so far been available for Italy. Like other Southern European countries, Italy is characterised by specific traditional family behavioural standards, that - at least until the last decade of the past century - held that the "indissoluble marriage" is the best arrangement for raising children (Rosina and Fraboni 2004). Marital dissolutions were therefore not numerous and socially relevant enough to be considered for specific empirical studies. However, marital instability has recently undergone a rapid increase (ISTAT 2007). Studying the implications of marital instability on fertility in Italy thus offers an opportunity to analyse the phenomenon in a country where there is a still relatively low social acceptance of marital instability. Our hypothesis is that, given the specific cultural context, the implications of marital instability on fertility may differ from those observed in other European countries, where separations and divorces are more common and more socially accepted. In comparison to those countries, we expect to find, for example, a stronger negative effect of separation on fertility due to more prudent post-dissolution reproductive behaviour among repartnered women. For a country such as Italy, which has one of the lowest fertility rates in Europe (EUROSTAT 2008), this means that union dissolution might be - at least temporarily - a new factor that could have a depressing effect on fertility.

We start by introducing the literature and the hypotheses (Section 2). We then describe the data and the methods used in the analyses (Section 3). In the following two sections, we present the results of our investigations: Section 4 analyses the predictors of a post-dissolution birth among separated women, and Section 5 investigates the quantitative impact of marital dissolution on the lifetime fertility of women. In the conclusion (Section 6), we comment on our findings. 


\section{Literature and hypotheses}

\subsection{Predictors of childbearing after a marital dissolution: Repartnering and children from the first marriage}

Studies on the family life-course factors that influence an individual's childbearing after a marriage dissolution are relatively numerous: the theme has relevance at both the micro level (individuals' family life course) and the macro level (the fertility of populations).

Because most of the existing literature focuses on separated women who have remarried, or who are at least in a cohabiting union, the fertility of stepfamilies has so far mainly been analysed. The focus in these studies is on how the stepchildren affect stepfamily fertility, and on how the exposure to a new period of risk of conception recaptures the fertility that may have been lost with the dissolution of the first marriage. In some studies, the analysis of reproductive behaviour is extended to take into account the entire period following the marital dissolution: in this case, the role played by a new partnership is also taken into account.

Repartnered women are expected to have greater chances of childbearing than women who are separated and living alone, due to their differing levels of exposure to intercourse and to the influence of social norms, which deem it desirable having children within a committed couple (sharing a child in a stable relationship may also be the result of a woman's rational choice, since she can thus share both monetary and non-monetary costs with the partner). Specifically, those women who have remarried are more likely to have a (further) child than those who are simply living with a partner (Vikat, Thomson, and Hoem 1999; Jefferies, Berrington, and Diamond 2000; Buber and Prskawetz 2000). This may be because marriage carries an explicit long-term commitment to stay together, and because remarried women may be selected as being more prone to forming a family, and thus to having children.

To what extent the characteristics (number and ages) of children born in the first marriage influence post-dissolution fertility has been the subject of considerable debate in the literature.

The most common approach considers the effects of the number of stepchildren on the risk of a first shared birth among repartnered women. Analyses with data only on women's children show mixed effects. On the one hand, some studies have found a clearly negative association between the risk of childbearing and the previous parity (Rindfuss and Bumpass 1977; Clarke et al. 1993; Lillard, Panis, and Upchurch 1994); on the other hand, other analyses have found a non-linear negative effect of such a parity (Wineberg 1990; Jefferies, Berrington, and Diamond 2000), while still others have demonstrated no effect (Griffith, Koo, and Suchindran 1985; Diamond, Clarke, 
and Clarke 1995). These latter results suggest that the effect of stepchildren may not be as strong as we could expect, and that the first shared child of a second union may have a unique value which interacts with the value of those children born during the first marriage. More in-depth studies examining the effect of the number of the children born to either partner of a stepfamily support this hypothesis, at least for some countries. Vikat and his colleagues (1999) found for Sweden that the risk of a first birth in a second or higher-order union is independent of the number of pre-union children. Buber and Prskawetz (2000) demonstrated for Austria that having pre-union children lowers the likelihood that a woman will have a child in a second union only if she already has more than one child. Beaujouan and Solaz (2008) found for France that the women with the highest risks of post-dissolution childbearing are in the following order: those without previous children, those with three children, and those with one or two children. Similarly, Thomson and her colleagues (Thomson 1997; Thomson and Li 2002; Thomson et al. 2002; Vikat, Thomson, and Prskawetz 2004; Henz and Thomson 2005; Thomson et al. forthcoming), analysing the stepfamily parity, found that stepchildren have a weaker negative effect on childbearing than shared children, and that, net of the stepchildren's contribution to the couple parity, the partners have an increased risk of having a first and, often, a second shared birth. Their interpretation is that stepchildren and shared children have unique effects on a couple's subsequent childbearing: in particular, a first shared child may symbolise the partners' commitment to their relationship, and confer the status of parent on one of the partners; while a second shared child may provide a full sibling to the first shared child.

The probability of having a child after separation may also be affected by the age of the children at marital dissolution, determining the length of a potential birth interval (Griffith, Koo, and Suchindran 1985). The empirical literature supports the hypothesis that the age of the children born in the first marriage influences the rate at which a first common child is conceived in a second union, but there is still no clear picture of the way in which this influence operates, or of the mechanism behind this phenomenon. The few studies on the topic suggest that the age of a woman's youngest child is inversely related to her probability of having a birth, thus indicating that women want to avoid long birth intervals (Jefferies, Berrington, and Diamond 2000; Buber and Prskawetz 2000; Beaujouan and Solaz 2008). The underlying hypothesis is that long extensions of childbearing periods are avoided as mothers - regardless of their marital status - do not wish to re-enter the childbearing phase later for economic or career reasons. Another argument is that the parents may wish to give previous children siblings of a similar age ("sibling effects"). However, some other studies have also suggested that the relationship may be more complex, and that there is at least some interaction with the parity (Jefferies, Berrington, and Diamond 2000). 
Not all of these results of the international literature can be extended to Italy due to the context-dependent costs of childbearing for separated women in this country. In general, childbearing has high personal costs for Italian mothers: compared to women in other European countries, they receive less help with childcare both from their partners and from the state. ${ }^{3}$ In addition, the separated women considered in our study experienced specific psychological costs of childbearing due to the fact that marital instability is a relatively recent phenomenon. Their generation came of age in a cultural context in which non-traditional family behaviours were still frowned upon by society. ${ }^{4}$ Thus, these additional context costs suggest that the effects of marital instability on a woman's fertility may differ from those observed in other European countries, where the costs of childbearing are in general lower, and marital dissolutions more common and more socially accepted. In particular, separated Italian women may be expected to display more cautious reproductive behaviours than their counterparts living in those countries.

Taking into account both the overview of international research and the specificities of Italian context, we propose the following hypotheses.

HP - 1.1 In line with the empirical literature, we assume that a new partnership is an important factor of exposure to the risk of conception after marital dissolution. As a consequence, even in Italy, the risk of experiencing a post-dissolution birth increases significantly if a separated woman enters a new union. However, given the specific traditional family context, we also assume that a new birth should be highly associated with a remarriage, while cohabitation should have a very weak positive association with the risk of experiencing a post-dissolution birth. For the same reasons, taking into account the meaning of divorce in the Italian process of marital dissolution, ${ }^{5}$ we assume

\footnotetext{
${ }^{3}$ Italy is known for providing very limited state support in early childcare services, and for the low effectiveness of its work-family balance policies (Esping-Andersen 1990). In addition, Italian fathers provide little help with childcare (Mencarini and Tanturri 2009). In terms of its early childcare services, Italy is characterised by a limited supply of public childcare for children under three years of age, both in terms of availability (only $6 \%$ of children attend a public crèche according to the OECD Family Database) and, the number of hours supplied on a day-to-day basis (Anxo et al. 2007). Childcare services are generally more compatible with part-time employment, which is relatively rare in Italy. In addition, the latest comparative studies have shown that the behaviour of fathers still conforms more than in other countries to traditional gender roles (Anxo et al. 2007; Smith Koslowski 2008).

${ }^{4}$ Of the women interviewed during the Italian FFS (1995), 83\% of them disagreed with the statement "marriage is an outdated institution" (De Sandre et al. 2000), and approximately $70 \%$ of them agreed with the statement "marriage is forever" (De Sandre et al. 1997).

${ }^{5}$ Under Italian law, the procedure for the dissolution of a marriage is divided into two consecutive steps: legal separation and divorce. Legal separation is the first step and is stated by the court with a specific separation decree: it allows the spouses to live separately, divides the property between them, and provides the child custody and the alimony arrangements. A divorce decree may be granted by the court only after three years of legal separation (until 1987, only after five years), and it dissolves any legal ties between the spouses deriving from their marriage. A de facto separation, as opposed to legal separation, is not legally recognized. Indeed,
} 
that having experienced a divorce increases the propensity to have children mainly indirectly, through its positive association with the risk of remarriage.

HP - 1.2 Although some studies show that the number of children born in the first marriage may have a non-linear negative effect, or even have no bearing on the risk of having a first post-dissolution birth, we hypothesise that the risk of having a first child after separation is negatively associated with the number of children previously born. We assume this because of the specific additional psychological costs of childbearing for separated Italian women. As a consequence, the effect of the unique value of the first shared birth of a stepfamily should have a negligible impact on our results.

HP - 1.3 Although some studies support the hypothesis that an inverse relationship exists between the age of the youngest child from the first marriage and the probability of having a post-dissolution child, we suspect that Italian women may worry about experiencing short birth intervals. Given the general and specific costs of childbearing, Italian separated mothers should prefer to space their children throughout their life course, and to conceive their first post-dissolution child when the last-born is old enough to require less intensive care by the mother. A further reason for this behaviour may be that separated mothers may be interested in reducing the discomfort of marital dissolution for their ever-born children while they are relatively young.

\subsection{The impact of marital instability on a woman's fertility}

There are several reasons why marital instability may be a causal factor resulting in lower fertility. Marital disruption that occurs during a woman's fecund years removes her from exposure to the risk of pregnancy, and may create one of the following scenarios: a) she does not repartner, and her parity is thus restricted to that achieved at the time of the dissolution of the marriage; b) she repartners, but enters this union later, at an age when she may be less fecund. Moreover, marital dissolution may be associated with lower fertility already during the first marriage, regardless of the duration of the marriage. On the one hand, marital discord may lead the couples to have less marital intercourse, and/or to limit their fertility (women in particular may be reluctant to have children in an unstable marriage because they are likely to be the parent with primary responsibility for children if the marriage dissolves). On the other hand, unhappy couples with few or no children may feel less reluctant to dissolve their marriage than similar couples with several children.

Other considerations indicate, however, that marital instability might have a much weaker depressing effect on fertility. In particular, the sudden change in exposure might

not all de facto separations in Italy are converted into legal separations, and not all legal separations become divorces (ISTAT 2004). 
not affect fertility very much if, as some studies on childbearing in step-families have pointed out, repartnering occurs soon after separation, sexual activity and intermarital pregnancy are common, and the individuals who repartner are motivated to have a second family irrespective of the size of their first family (Thomson and Li 2002; Vikat, Thomson, and Prskawetz 2004). As a consequence, the completed fertility among everseparated individuals might be almost the same as the completed fertility of their continuously married counterparts.

The body of literature that deals specifically with this topic is not very large, and the results of these studies are far from clear. Early empirical studies that have attempted to analyse the impact of marital instability on the lifetime fertility of individuals have shown that marital dissolution results in an overall loss in fertility. Lesthaeghe and Moors (1994) have indeed found that, in Germany, Belgium, France, and the Netherlands, separated or divorced people have a much greater chance of ending up childless than married people. Analyses conducted using American data have shown that women in discontinuous marriages have fewer children than those in continuous marriages (Lauriat 1969; Cohen and Sweet 1974; Thornton 1978; Wineberg 1988). However, most of them have also shown that repartnered women recapture most of their lost fertility. In line with this observation, a descriptive study for France showed that, compared with people who remain in a first marriage, individuals who are divorced experience only a slight reduction in fertility if they enter new unions (Leridon 1990). More recent studies have produced mixed results. On the one hand, Thomson et al. (forthcoming) found using French data that stable unions produced more children in total than unstable unions: i.e., their analysis showed that women who repartner are more likely to have additional births than those who do not repartner, but that these additional births are still not sufficient to compensate for "lost" births in stable unions. On the other hand, some studies have suggested that the negative association between marital dissolution and fertility may be over-emphasised. For example, Billari (2005), after examining some descriptive results by Pinnelli et al. $(2002)^{6}$ on FSS data, found that the share of women who have their second birth in a second union is relatively high, and that, in some countries (France, Hungary, and the United States), the share is significantly higher than that of women at the birth of the first child. In addition, Beaujouan and Solaz (2008) found for France that, while women who underwent a separation generally show a reduced fertility, men who repartner achieve the same fertility as never-separated men. Similar results were found by Jansen and colleagues (2008).

Isolating the effect of marriage dissolution on individuals' fertility is not easy, because there are a great many processes and factors that may confound and obscure the

\footnotetext{
${ }^{6}$ Pinelli and colleagues (2002, page 81) presented the percentage distribution of first and second births according to the type of union in five countries.
} 
relationship. Indeed, the fertility of separated women is the result of their reproductive behaviour, both during the first marriage and after the first marriage. Moreover, marital dissolution may be more common among certain segments of the population than among others, and these groups are in turn known to have higher or lower fertility than those who are less likely to divorce. Lauriat's work (1969) showed, for example, that for younger cohorts, the higher fertility seen among women who divorced relative to the fertility of women who remained in intact marriages is largely explained by their earlier ages at marriage. Other sources of heterogeneity have been suggested by analyses using simultaneous models. A study on fertility in Brazil (Leone and Hinde 2007) indicated that the higher fertility of separated women relative to the fertility of married women may be the result of a greater propensity among separated women for having children. A study based on data from Italy and Spain (Coppola and Di Cesare 2008) found that, in Italy, individuals who are more oriented towards family values are more willing to attain higher fertility and to stay in longer-lasting unions; however, this hypothesis was not confirmed in Spain.

With respect to Italy we assume that, given the specific cultural context described in Section 2.1, marriage dissolution lowers the cumulated fertility of women, regardless of whether or not they have repartnered. Our specific hypotheses are as follows:

HP 2.1 - Women in unstable first marriages who do not repartner during their fecund years produce fewer children than those whose first marriages remain intact during their reproductive years. Net of other background factors, the loss of exposure to the risk of pregnancy as a result of the disruption of the first marriage should explain a large part of the fertility differentials.

HP 2.2 - Women in unstable first marriages who repartner at fecund ages produce more children than their counterparts who do not repartner. This assumption is based on two arguments: a) a new union reduces the loss of exposure to conceiving due to marriage dissolution; b) the new union (especially if it is formal) reduces the psychological costs of childbearing for a woman with non-traditional family behaviours (see also HP 1.1).

HP 2.3 - Women who repartner at fecund ages produce, on average, fewer children than women in stable first marriages. Given the context-related costs specific to Italy, we assume that the loss of childbearing potential while outside a union is not (or is not totally) made up for by the "unique value effect of the (first) shared child" (see also HP 1.2) observed in other European countries. 


\section{Data, methods, and measures}

\subsection{Data and sub-samples}

The data come from the survey "Family and Social Subjects," which was conducted in Italy in 2003 by the National Statistical Institute (ISTAT). The survey encompasses a representative sample at the national level of about 20,000 households, with detailed social and family information provided for each household member. In particular, for women over the age of 15 , retrospective data on union and reproductive biographies are available. Both the years of the beginning and of the dissolution of each union (marriage or cohabitation) are reported. For each marital dissolution, the reason for dissolution (widowhood or separation) is known. In the case of separation, up to three dates at most are recorded (the years of de facto separation, legal separation, and divorce). In order to mark the end of the first marriage, the date of the de facto separation was chosen among the available dates. ${ }^{7}$ For each live birth, the month and the year of birth are known, as well as the possible date of death. Thus, the number and the ages of the children still alive at the moment of separation ${ }^{8}$ are also known. Unfortunately, in the case of the second union, information on the partner's previous children is not available.

One of two analytic samples were considered depending on the aims of the analysis. The investigation of the effects of separation on cumulated fertility considered a sub-sample of ever-married women, i.e., those who were still in an intact first marriage, or who had experienced a de facto separation ${ }^{9}$ (widows were not considered). In order to remove cases with possible problems of data quality (elderly women who, at the time of the interview, may have presented recall problems for the retrospective data), women aged 25-64 at the date of the interview were considered. ${ }^{10}$ As we also discarded women (110 cases) who were older than age 40 at their first marriage (to avoid taking into account first marriages that mainly spanned the non-reproductive

\footnotetext{
${ }^{7}$ There are several reasons why we chose the de facto separation as the event which represents the dissolution of a marriage. It is the event marking the end of the spouses' co-residence, and, thus, the start of the period at risk for forming subsequent (informal) unions ( $21 \%$ of the second unions were entered into before the legal separation). Consequently, at least for these cases, the period at risk for childbirth had begun before the legal separation. In addition, choosing a later date would have reduced the sample to be analysed (i.e., if we had used the date of legal separation, women who, at the time of the interview, had experienced only de facto separation would not have been included in the sample).

${ }^{8}$ Henceforth, we refer to the children still alive at the moment of separation simply as "children at separation."

${ }^{9}$ In the cases in which the date of de facto separation was missing, a probabilistic imputation method (Rubin 1987) was used. For details about this point, see Meggiolaro and Ongaro, 2008.

${ }^{10}$ Women under age 25 at the time of the interview were not included in our analysis because of their short family life course.
} 
years), we chose to focus in the end on 10,567 women. Table 1 (column 1) lists the socio-demographic characteristics of this sample. More than half of the women were born before 1960, and almost 30\% were born before 1950. Not surprisingly, therefore, their educational levels were relatively low (more than half had a low level of education), less than $50 \%$ were participating in the labour market at the time of their first marriage, and most of them (almost 60\%) married when they were under age 25 . Of these 10,567 women, 829 (almost $8 \%$ ) were separated, ${ }^{11}$ i.e., they had experienced the dissolution of their first marriage. A description of this subsample is shown in column 2 of Table 1. At the time of separation, most of these women were ages 25-39 and had children (three out of four). In addition, most of them (83\%) had been legally separated at the time of the interview, but only $36 \%$ were also divorced. Relatively few separated women had entered a second union $(24 \%)$ or a second marriage $(9 \%)$ at the time of the interview, and the percentage of those interviewed who had (at least) one child after the first marital break-up was also small (14\%, and 3.6\% with more than one child). ${ }^{12}$ In line with the literature (Vignoli and Ferro 2009), separated women were found to be more highly educated and more likely to be employed than women in intact marriages. This may be at least partially due to the fact that the former belong to a younger cohort than the latter. In addition, a greater percentage of the separated women lived in Northern Italy. No great differences were, however, found in the age at first marriage.

The sub-group of women who dissolved their first marriage before the age of 40 were considered for the analyses that explored how a woman's family trajectory influences the risk of having a child after the first marital disruption. The characteristics of this sub-group, which numbered 633, are described in column 3 of Table 1 . In comparison to the separated women of the previous group, they belong to a younger birth cohort (almost 60\% were born after 1960), had a lower number of children at separation (31\% had no children), and experienced divorces, second unions, and second marriages in greater percentages. Lastly, more of them had a child after the first marital break-up (almost 19\%). However, no great differences were found in the other characteristics.

\footnotetext{
${ }^{11}$ Henceforth, de facto separation simply means separation, and women who underwent (at least) a de facto separation are simply called separated.

${ }^{12}$ Twelve women had a child within one year after separation, and did not cohabit after thereafter. We assumed that these women had the child within the first marriage, and they are therefore not considered in this percentage. It could be, however, that some of these births may have resulted from extramarital affairs; in this case, they may be the reason rather than the effect of the separation itself. Thus, not considering these women in our analyses again appears to be the more appropriate choice. Another 10 women who had a child within one year after a separation, but who also repartnered, are considered in the percentage of women with a child after a separation, and the new child is assigned to the new partner. In fact, these women may have had those children within the first marriage. However, the numbers are so small that these choices would not change the results.
} 
Table 1: Women aged 25-64 at interview who entered first marriage before the age of 40

\begin{tabular}{lccc}
\hline Characteristics & $\begin{array}{c}(1) \\
\text { Ever married } \\
\text { women }\end{array}$ & $\begin{array}{c}(2) \\
\text { Women who } \\
\text { underwent } \\
\text { separation }\end{array}$ & $\begin{array}{c}\text { Women who } \\
\text { underwent } \\
\text { separation before 40 }\end{array}$ \\
\hline Age at first marriage & & & 66.8 \\
Under 25 & 59.9 & 63.1 & 23.4 \\
$25-29$ & 29.3 & 24.8 & 9.8 \\
Over 30 (but under 40) & 10.8 & 12.1 & 10.9 \\
Birth Cohort & & & 31.0 \\
Until 1950 & 27.1 & 18.2 & 43.6 \\
1950-1959 & 28.2 & 36.6 & 14.5 \\
1960-1969 & 30.3 & 34.1 & 55.8 \\
1970 and after & 14.4 & 11.1 & 17.7 \\
Region of residence $\dagger$ & & & 26.5 \\
North & 41.9 & 54.6 & 10.4 \\
Centre & 18.4 & 18.9 & 34.5 \\
South & 39.7 & 26.4 & 55.1 \\
Education & & & 51.8 \\
High (university) & 9.1 & 11.3 & \\
Middle (high school) & 27.0 & 33.4 & \\
Low (junior school or less) & 63.9 & 55.3 & \\
\% employed at the time of first marriage & 46.2 & 51.7 & \\
\% with a separation & 7.9 & & \\
\hline
\end{tabular}


Table 1: (Continued)

\begin{tabular}{|c|c|c|c|}
\hline Characteristics & $\begin{array}{c}(1) \\
\text { Ever married } \\
\text { women }\end{array}$ & $\begin{array}{c}\text { (2) } \\
\text { Women who } \\
\text { underwent } \\
\text { separation }\end{array}$ & $\begin{array}{c}\text { (3) } \\
\text { Women who } \\
\text { underwent } \\
\text { separation before } 40\end{array}$ \\
\hline \multicolumn{4}{|l|}{ Age at separation } \\
\hline Under 25 & & 10.6 & 13.9 \\
\hline $25-29$ & & 22.6 & 29.5 \\
\hline $30-34$ & & 23.3 & 30.5 \\
\hline $35-39$ & & 19.9 & 26.1 \\
\hline $40-44$ & & 13.4 & \\
\hline Over 45 (and <65) & & 10.2 & \\
\hline \multicolumn{4}{|l|}{ Number and age of children at separation } \\
\hline No children & & 26.1 & 31.0 \\
\hline 1 child under 6 & & 19.2 & 23.8 \\
\hline 1 child over 6 & & 18.1 & 16.4 \\
\hline 2 or more children with at least one under 6 & & 13.6 & 16.9 \\
\hline 2 or more children over 6 & & 23.0 & 11.9 \\
\hline$\%$ with legal separation & & 82.6 & 85.8 \\
\hline$\%$ with a divorce & & 35.7 & 40.7 \\
\hline$\%$ with a second union & & 24.0 & 29.1 \\
\hline$\%$ with a second marriage & & 8.8 & 11.4 \\
\hline$\%$ with children after separation & & 14.5 & 18.8 \\
\hline $\mathrm{N}^{\circ}$ of cases $($ Total $=100)$ : & 10,567 & 829 & 633 \\
\hline
\end{tabular}

† Conforming to the standard classification, Northern Italy includes the regions of Piemonte, Valle d'Aosta, Lombardia, Trentino Alto Adige, Veneto, Friuli Venezia Giulia, Liguria, and Emilia Romagna; Central Italy includes Toscana, Umbria, Marche, and Lazio; Southern Italy includes Abruzzo, Molise, Campania, Puglia, Basilicata, Calabria, and the two main islands (Sicilia and Sardegna). 


\subsection{Methods and measures}

\subsubsection{Modelling the predictors of childbearing after marital disruption}

We used discrete time event history analysis techniques to analyse the determinants of the (first) birth after separation. ${ }^{13}$ In particular, logistic regressions were applied to person-year data (Yamaguchi 1991). The discrete-time logistic regression model takes the following form:

$$
\log \left(\frac{p_{t}}{1-p_{t}}\right)=\alpha+\beta X_{t}+\gamma Z_{t}+\varepsilon
$$

where $p_{t}$ is the probability of giving birth in year $t ; \alpha$ is the intercept; $\beta$ and $\gamma$ are vectors of estimated coefficients; $X_{t}$ is the time since marital dissolution (in this case, up to two years; 3-5 years; 6-9 years; 10 years or more); and $Z_{t}$ is a (row) vector of covariates, which are either fixed or time dependent.

Covariates of interest are represented by a woman's children at marital disruption (number and age of the children born during the first marriage), and a woman's partnership trajectory following separation (whether or not the woman is divorced, and whether she entered into a second union). For the children, a categorical covariate was built that describes both the number of children (zero, one, two or more) and the age of the youngest child (up to five, six or more) at the time of the mother's separation. The experience of a divorce was measured using a time-varying covariate ${ }^{14}$. Lastly, two time-dependent covariates reported whether a woman entered into a second union or a second marriage at a fecund age (here, the age is fixed as under 40). Thus we can control for-at least in part - the circularity of the relationship between the union/marriage and post-dissolution childbearing: there may indeed be an issue of circular causality here, given the possibility that actual pregnancies may lead to divorce or repartnering, rather than divorce or repartnering preceding fertility. In addition, the joint use of the two covariates makes it possible to have a kind of ordinal covariate, which expresses how the risk of childbearing changes when moving from cohabitation to marriage.

In addition to these covariates, the woman's age at separation and some other control variables, representing the socioeconomic and contextual background, were also included in the model. The woman's age at separation was used as a proxy for the probability of conceiving, and was grouped into three categories (under 30, 30-34, 35-

\footnotetext{
${ }^{13}$ A similar approach has been used by Jefferies and colleagues (2000) with reference to British women.

${ }^{14}$ This and the other time-varying covariates were measured at year $t-1$.
} 
39). The context is represented by a woman's birth cohort (before/after 1960) and the geographic area of residence (North, Centre, South). Socioeconomic factors are described through the women's education at the time of interview (university or high school [middle-high] and junior school [low] $)^{15}$ and employment status (employed/not employed, in a time-varying specification). In Italy, all of these factors have been found to be associated with the risk of marital dissolution among women (Vignoli and Ferro 2009), as well with women's fertility (Kertzer et al. 2009).

\subsubsection{Modelling the effects of marital dissolution on cumulated fertility}

A Poisson regression model (Cameron and Trivedi 1998) was used to estimate the impact of separation on a woman's fertility, controlling for the effects of potential disturbance factors. Since it seeks to model counts (variables with only non-negative integer values), this model can be considered adequate for studying cumulated fertility. In particular, by indicating with $y$ the variable describing the cumulated fertility (number of children) up to a certain age, the model assumes that the probability that $y$ is equal to some number $r$ is given by:

$$
\operatorname{Pr}(y=r)=\frac{\lambda^{r} e^{-\lambda}}{r !} \quad r=0,1,2, \ldots
$$

where $\lambda$ is the expected value (mean) of $y$. Although $y$ can only take on integer values, $\lambda$ may be any positive number. The model specifies how parameter $\lambda$ depends on the explanatory variables. First, $\lambda_{i}$ is written with subscript $i$ to allow the parameter to vary across individuals. Then, because $\lambda$ cannot be less than zero, it is standard to let $\lambda$ be a loglinear function of $x$ variables:

$$
\log \lambda_{i}=\beta_{0}+\beta_{1} x_{i 1}+\beta_{2} x_{i 2}+\ldots+\beta_{k} x_{i k}
$$

When interpreting coefficients, we find that if we calculate $100\left(e^{\beta}-1\right)$, we get the percentage change in the expected number of children with each one-unit increase in the independent variable.

The dependent variable $y$ is the cumulated fertility up to the age at the time of the interview. It was regressed on a set of covariates representing the woman's union history up to her age at the time of the interview, and various other potentially

\footnotetext{
${ }^{15}$ In the final specification, the education categories were only two (middle-high, low), as in preliminary analyses the medium and high levels showed similar effects.
} 
confounding variables (Cohen and Sweet 1974). Our main explanatory covariate was the union biography of the respondent up to the time of the interview. Three different patterns were considered: (i) no separation at a fecund age (women who were still in an intact first marriage, or who separated after age 40$)^{16}$; (ii) a separation at a fecund age, but with no second union (marriage or cohabitation), or a second union at a nonreproductive age (a total of 449 women had no second union, while a total of 28 women repartnered at age 40 or above); (iii) both a separation and a second union at a fecund age (a total of 156 women repartnered when they were under age 40). As a consequence, we take into account not only the separation and entry into a new union, but also whether the time spent in the second union coincided at least partially with the women's reproductive years. ${ }^{17}$

Three other covariates were computed in order to control for the woman's exposure to the events of interest: the woman's age at marriage, her age at the time of the interview, and the number of reproductive years a woman spent in a union. The age at a woman's first marriage, as well as her age at the time of the interview, may be considered different proxies for her attitudes about having children. More importantly, the age at marriage and the age at the time of the interview together determine the time during which the woman may experience the main events under study. The age at the time of the interview, in particular, controls for the different (censored or not) lifecourse lengths that characterise the sample of women. Reproductive time spent in a union expresses the years spent in a union by a woman of reproductive ages (18-44). This variable is equivalent to the number of reproductive years spent in the first marriage for women in continuous marriages, as well as for women who separated at non-reproductive ages. It also expresses the number of reproductive years spent in the first marriage for separated women without a second union; and the years spent in the first marriage, plus the reproductive years spent in the second union, for women who repartnered at fecund ages. In the analyses, the number of reproductive years spent in a union were considered as a categorical variable with three categories (0-3 years; 4-6 years; 7-9 years; 10 or more years).

Besides these four covariates, other potentially confounding background characteristics (education, employment status at first marriage, ceremony of first marriage, presence of siblings, separated parents) were also considered.

\footnotetext{
${ }^{16}$ The number of women with a marital disruption after age 40 was 201.

${ }^{17}$ This attention paid to both union biography following marital disruption and the woman's reproductive age is one of the main differences between this study and the work of Cohen and Sweet (1974).
} 


\section{Analysing the predictors of childbearing after marital disruption}

In this section, we analyse how the woman's family life-course factors (i.e., the characteristics of the children at separation and the union history following the marital dissolution) influence the risk of a post-dissolution birth among women who ended their first marriage when they were under age 40, and who were ages 25-64 at the time of the interview ${ }^{18}$ (see Subsection 3.1). We first present the results of some univariate analyses that describe how the woman's status at separation is associated with the likelihood of childbearing after the dissolution of the marriage. We then show the results of some logistic models (see Subsection 3.2.1), with the goal of isolating the effects of the covariates of interest, net of confounding factors.

\subsection{A preliminary descriptive analysis}

Figure 1 shows the proportions of women who did not have a post-dissolution child during the 15 years following the marital dissolution. The figures were estimated ${ }^{19}$ according to the two factors describing the woman's status at separation: her age (Figure 1.a) and the characteristics of the children (parity and the age of the youngest child) born during her first marriage (Figure 1.b).

As expected, we found a clear negative association between a woman's age at separation and subsequent fertility. For example, five years after separation, $21.2 \%$ of women who were under age 30 at the time of separation have a child; but this figure decreases to $3.7 \%$ for women who dissolved their first marriage when they were 35-39. The characteristics of the children at the time of the break-up also influence the risk of childbearing after marital dissolution. In particular, the women who are at greatest risk of having a child after separation are women with no children or with only one child, especially if the child is under age six. However, these results do not take into account the effects of other factors: for example, the effect of age may be confounded by the associated characteristics of the children; and, at the same time, the effect of the children may be influenced by the correlated age of the mother at the time of separation.

\footnotetext{
${ }^{18}$ Women who had no children after the first marital dissolution were censored at the time of interview, or, if they were over age 50 at the time of the interview, they were censored at age 49.

${ }^{19}$ The survival curves used were calculated with the life-table method (Blossfeld and Rohwer 2002).
} 
Figure 1: Proportions of women who did not experience a post-dissolution birth in the 15 years following marital disruption, according to the women's status at separation (estimates from life-table method).

a) Woman's age

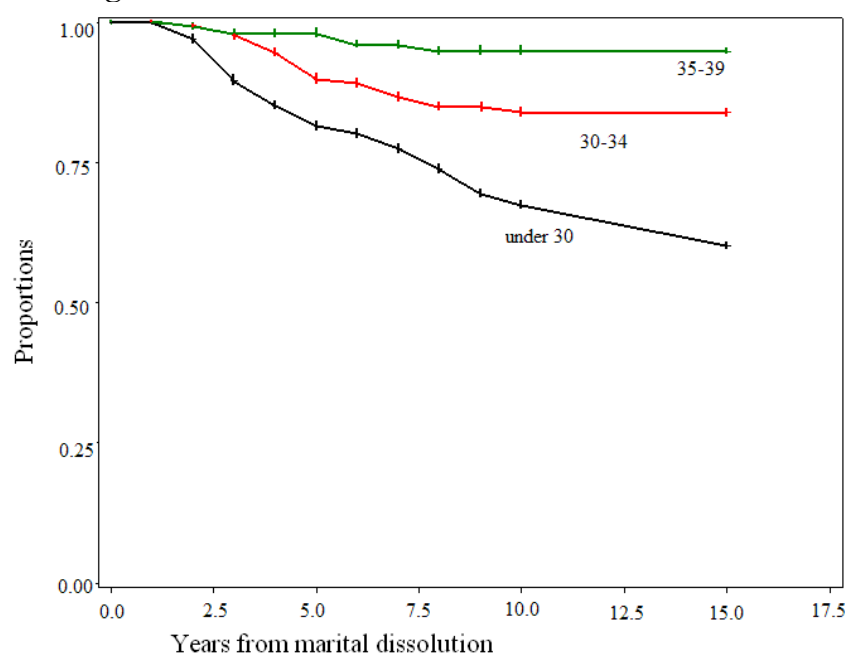

b) Parity and age of the youngest child

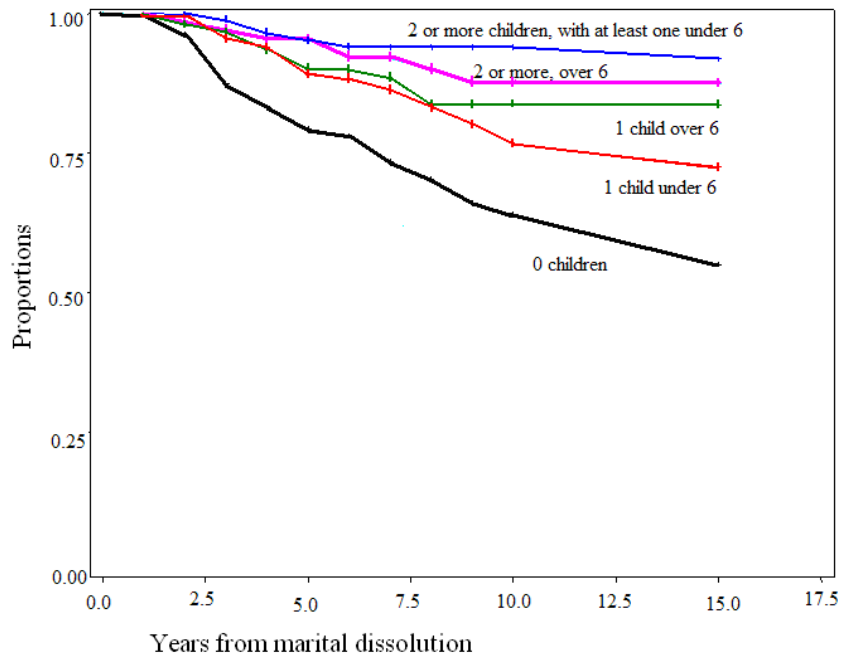




\subsection{Modeling the predictors of childbearing after marital disruption}

Table 2 lists the results of four models that estimate the likelihood of having a postdissolution child, according to different sets of explanatory variables.

Table 2: Parameter estimates from logistic models analysing the predictors of a post-dissolution birth (women under age 40 at separation).

\begin{tabular}{|c|c|c|c|c|}
\hline & Model 1 & Model 2 & Model 3 & Model 4 \\
\hline Intercept & $-5.82^{* \star}$ & $-6.22^{* \star}$ & $-6.47^{* *}$ & $-5.24^{\star *}$ \\
\hline \multicolumn{5}{|c|}{ Duration since marital disruption (ref: 10 years or more) } \\
\hline$<2$ years & 0.05 & 0.45 & $0.86^{\dagger}$ & 0.68 \\
\hline $3-5$ years & $1.61^{* *}$ & $1.95^{\star *}$ & $2.15^{\star *}$ & $2.05^{* *}$ \\
\hline $6-9$ years & $1.17^{\star *}$ & $1.28^{* *}$ & $1.32^{* *}$ & $1.28^{* *}$ \\
\hline \multicolumn{5}{|l|}{ Age at separation (ref: $35-39$ ) } \\
\hline Under 30 & $1.92^{* *}$ & $1.90^{* *}$ & $1.13^{*}$ & $0.91^{\dagger}$ \\
\hline 30-34 years & $1.05^{*}$ & $1.04^{*}$ & 0.62 & 0.52 \\
\hline \multicolumn{5}{|c|}{ Number and age of children at separation (ref: 0 ) } \\
\hline 1 child under 6 & $-0.78^{* *}$ & $-0.75^{* *}$ & $-0.69^{* *}$ & $-0.73^{* *}$ \\
\hline 1 child over 6 & $-0.52^{\dagger}$ & -0.47 & -0.46 & $-0.58^{\dagger}$ \\
\hline $\begin{array}{l}2 \text { or more children, with at least one } \\
\text { under } 6\end{array}$ & $-1.88^{* *}$ & $-1.77^{* *}$ & $-1.19^{* *}$ & $-1.35^{\star *}$ \\
\hline 2 or more children, over 6 & -0.55 & -0.52 & -0.59 & $-0.81^{\dagger}$ \\
\hline \multicolumn{5}{|l|}{ Experience of divorce $\ddagger$ (ref: no) } \\
\hline Yes & & $0.58^{*}$ & -0.08 & -0.05 \\
\hline \multicolumn{5}{|c|}{ Repartnering at reproductive age $\ddagger$ (ref: no) } \\
\hline Yes & & & $2.05^{\star *}$ & $2.14^{* *}$ \\
\hline \multicolumn{5}{|c|}{ Remarriage at reproductive age $\ddagger$ (ref: no) } \\
\hline Yes & & & $0.82^{*}$ & $0.82^{*}$ \\
\hline \multicolumn{5}{|l|}{ Birth cohort (ref: after 1960) } \\
\hline Before 1960 & & & & -0.26 \\
\hline \multicolumn{5}{|l|}{ Residence region (ref: South) } \\
\hline North & & & & $-0.47^{\dagger}$ \\
\hline Centre & & & & $-0.70^{*}$ \\
\hline \multicolumn{5}{|l|}{ Educational level (ref: low) } \\
\hline Middle-high & & & & -0.17 \\
\hline \multicolumn{5}{|c|}{ Employment status $\ddagger$ (ref: not employed) } \\
\hline Employed & & & & $-0.59^{* *}$ \\
\hline
\end{tabular}

$\ddagger$ Time-varying variables.

$\dagger=p<.10,{ }^{*}=p<.05,{ }^{* *}=p<.01$ 
Model 1 considers only the effect of the woman's status at the time of the dissolution of the marriage. As was illustrated in Figure 1, the woman's age at separation is negatively associated with the risk of a post-dissolution birth. After this factor has been controlled for, the results suggest that there is a complex relationship between the characteristics of the children born during the first marriage and the likelihood of having a child after separation. Compared to women who have no children (reference category), those women with children of pre-school age show a probability of having a post-dissolution child that decreases with the parity. As this depressing effect is much weaker for women whose children are (all) ages six or older, it would seem that, in line with the results of Jefferies and colleagues (2000), the effect of parity on the subsequent fertility interacts with the ages of the children at separation.

Models 2 and 3 include the effects of the covariates representing the woman's union trajectory following the separation. As expected, the experience of divorce is found to be positively associated with the probability of having a post-dissolution child (Model 2) but its effect becomes insignificant when the two time-dependent covariates measuring the woman's repartnering behaviour are added (Model 3). As expected, and as found in the literature (see, for example, Brown 2000), repartnering after separation is closely (and positively) associated with giving birth. Remarried women are the most likely to have a child: after controlling for entry into a second union, the probability of having a child among women who had also married was found to be $2.27[\exp (0.82)]$ times higher than among women who had not married. On the other hand, cohabiting women were shown be significantly more likely to have a post-dissolution child than women who did not repartner $[7.77=\exp (2.05)]$. This means that, contrary to our hypotheses, even in a Mediterranean country such as Italy, cohabitation alone may be an important predictor for post-dissolution childbearing. Model 3 also shows that the effect of the woman's age at separation is partly explained by the repartnering behaviour: ${ }^{20}$ after controlling for this factor, the negative association between age at separation and childbearing was shown to be less strong, and the effect was found to be limited to the youngest ages.

Finally, Model 4 presents the effects of the family life course when socioeconomic and contextual background covariates are added. In this model, the effects of both the woman's age at marital disruption and her union status after separation do not greatly change relative to the previous models. The age at separation is only weakly relevant for the risk of a post-dissolution birth, as most of its effect is mediated by other covariates (repartnering behaviour and background factors). Moreover, getting married, but also cohabiting, greatly increases the risk of post-dissolution childbearing. Lastly, the effect of previous parity seems to interact with the age of the children: the

\footnotetext{
${ }^{20}$ Indeed, earlier studies showed that a relatively old age at separation decreases the woman's chances of repartnering (Meggiolaro and Ongaro 2008).
} 
depressing effect of parity on the risk of having a subsequent child seems to be stronger for women with children of pre-school ages than for women whose children are ages six or older. However, these results are not sufficient to allow us to conclude that, at least among women with children of pre-school age, a linear association exists between previous parity and post-dissolution childbearing. More in-depth analyses designed to verify the statistical significance of the differences between couples of parameter estimates have indeed shown that women with children (whatever their number and ages) are not significantly different from each other, and that the only statistically significant difference is between women with and without children. Thus, our results show that, contrary to our assumption, the parity effect does not appear to be linear: separated women with no children have the highest risk of having a subsequent child, but those with children seem to have the same probability of childbearing, regardless of the number and the ages of children. ${ }^{21}$

In summary, the results of our analyses only partially confirm our hypotheses and they suggest that, even in a country with a still-low diffusion of marital instability, childbearing after separation may be driven by non-traditional family behaviours.

\section{Analysing the effects of marital dissolution on cumulated fertility}

In this section, we are interested in investigating the consequences of separation on women's fertility. As was noted in Subsection 3.1, the analysis is carried out on evermarried women aged 25-64 at the time of the interview, and who were under age 40 at time of their first marriage. We first present the results of a descriptive analysis that describe the fertility reached by women at given time periods since the first marriage, according to their marital histories. We then show the results of some Poisson models (see Subsection 3.2.2) that aim to isolate the effects of the separation on women's cumulated fertility, net of other disturbing factors.

\footnotetext{
${ }^{21}$ The relatively small sample size did not allow us to test the proportionality assumption for this variable.
} 


\subsection{A first look at the differences in fertility between women in continuing and interrupted marriages}

Table 3 lists the (average) number of children of women by marriage cohort and years elapsed since the first marriage. ${ }^{22}$ In order to take into account the different outcomes of the first marriage, we distinguished between women whose marriages ended due to separation, and women whose marriages were still intact at the date of the interview. Obviously, our analysis is constrained by the fact that, as the year of marriage drew closer to the year of interview, separated women were selected for both increasingly short durations since the first marriage, and/or for younger ages at the time of separation. Nevertheless, for the non-censored durations, results show that, in each marriage cohort and at each duration, women who are undergoing marital dissolution have, on average, fewer cumulated children than women who are still married at the time of the interview. Thirteen years after their first marriage, for example, separated women whose wedding was celebrated in the 1980s show a cumulated fertility that is approximately 0.5 children lower than that of their counterparts who remained in an intact marriage up to the time of the interview. This leads us suppose that-in line with the findings of Beaujouan and Solaz (2008) for French women-Italian separated women may have, on average, a lower completed fertility than those in continuous marriages. Interestingly, the (cumulated) fertility of women who eventually separated is shown to be lower than that of women in continuous marriage already during the first years following the wedding. This suggests that separated women might have a lower fertility already during the first marriage. However, all these differences do not take into account several potentially disturbing factors. Differences at early durations may, for example, be explained by structural factors not controlled for by the descriptive analysis, like a woman's human capital or her area of residence (however, the age at first marriage does not seem to differ greatly between separated and non-separated women). More generally, the descriptive analyses do not consider the possibility that separated women are a heterogeneous group with respect to both their ages at separation, and their union histories subsequent to marital dissolution.

${ }^{22}$ The last figures of each column (in bold) refer to the duration censored by the date of interview. 
Table 3: Mean number of children born to an ever-married woman by years since the first marriage, marriage cohort, and marital status. Women aged 25-64 at the interview who married while under age 40 .

\begin{tabular}{|c|c|c|c|c|c|c|c|c|c|c|c|c|}
\hline \multirow{3}{*}{$\begin{array}{l}\text { Marriage cohort } \\
\text { Years between marriage } \\
\text { and interview } \\
\text { Separation }\end{array}$} & \multicolumn{2}{|c|}{ Up to 1979} & \multicolumn{2}{|c|}{$1980-1984$} & \multicolumn{2}{|c|}{$1985-1989$} & \multicolumn{2}{|c|}{$1990-1994$} & \multicolumn{2}{|c|}{ 1995-1999 } & \multicolumn{2}{|c|}{2000 and after } \\
\hline & \multicolumn{2}{|c|}{ More than 24} & \multicolumn{2}{|c|}{$19-23$} & \multicolumn{2}{|c|}{$14-18$} & \multicolumn{2}{|c|}{$9-13$} & \multicolumn{2}{|c|}{$4-8$} & \multicolumn{2}{|c|}{$0-3$} \\
\hline & No & Yes & No & Yes & No & Yes & No & Yes & No & Yes & No & Yes \\
\hline \multicolumn{13}{|l|}{ Years since marriage $\left(^{*}\right)$} \\
\hline Up to 3 & 1.07 & 0.97 & 0.94 & 0.74 & 0.90 & 0.68 & 0.87 & 0.68 & 0.81 & 0.53 & 0.57 & 0.29 \\
\hline Up to 8 & 1.79 & 1.49 & 1.60 & 1.14 & 1.56 & 1.12 & 1.53 & 1.00 & 1.28 & 0.73 & & \\
\hline Up to 13 & 2.05 & 1.71 & 1.87 & 1.31 & 1.81 & 1.33 & 1.72 & 1.10 & & & & \\
\hline Up to 18 & 2.12 & 1.79 & 1.95 & 1.38 & 1.84 & 1.41 & & & & & & \\
\hline Up to 23 & 2.14 & 1.80 & 1.96 & 1.38 & & & & & & & & \\
\hline $24+$ & 2.15 & 1.81 & & & & & & & & & & \\
\hline $\begin{array}{l}\text { No. of marriages } \\
\text { (women) }\end{array}$ & 4,509 & 346 & 1,216 & 146 & 1,133 & 126 & 1,174 & 116 & 1,027 & 81 & 679 & 14 \\
\hline $\begin{array}{l}\text { Mean age at first } \\
\text { marriage }\end{array}$ & 22.34 & 21.90 & 23.26 & 23.38 & 24.38 & 24.22 & 25.60 & 25.72 & 27.01 & 27.29 & 28.73 & 29.79 \\
\hline $\begin{array}{l}\text { Mean duration of } \\
\text { marriage }\end{array}$ & 32.44 & 14.57 & 21.08 & 10.89 & 16.00 & 7.89 & 11.03 & 5.39 & 6.00 & 2.83 & 1.78 & 1.18 \\
\hline Mean age at separation & & 36.47 & & 34.27 & & 32.12 & & 31.11 & & 30.12 & & 30.78 \\
\hline $\begin{array}{l}\% \text { with a second union } \\
\quad(\text { age }<40)\end{array}$ & & 15.0 & & 16.4 & & 32.5 & & 23.2 & & 14.8 & & 0.0 \\
\hline
\end{tabular}

$\left.{ }^{*}\right)$ censored data in bold.

\subsection{Modelling the effect of marital dissolution on cumulated fertility}

Table 4 lists the results of six Poisson regression models ${ }^{23}$ designed to estimate the effect of separation on a woman's cumulated fertility: Models 1 to 3 present the main results, while Models 4 to 6 are additional models that enable us to better understand if and how the loss of exposure to the risk of conception plays a role in reducing the fertility of separated women.

${ }^{23}$ We include a scale parameter to correct for the lack of efficiency due to overdispersion. 
Table 4: Poisson regression models analysing the cumulated fertility according to women's marital status and potential confounding factors (coefficient estimates).

\begin{tabular}{|c|c|c|c|c|c|c|}
\hline & Model 1 & Model 2 & Model 3 & Model 4 & Model 5 & Model 6 \\
\hline Scale parameter & 0.72 & 0.70 & 0.67 & 0.67 & 0.67 & 0.66 \\
\hline Intercept & $0.75^{\star \star}$ & $0.47^{* *}$ & $0.59^{\star \star}$ & $0.20^{* *}$ & $0.38^{\star \star}$ & $0.35^{\star \star}$ \\
\hline \multicolumn{7}{|l|}{ Age at interview (ref: over 50) } \\
\hline Under 34 & $-0.58^{\star *}$ & $-0.51^{\star *}$ & $-0.51^{\star \star}$ & & $-0.12^{\star \star}$ & $-0.18^{\star \star}$ \\
\hline $35-39$ & $-0.23^{\star *}$ & $-0.16^{\star \star}$ & $-0.16^{\star \star}$ & & $-0.10^{\star \star}$ & $-0.10^{\star \star}$ \\
\hline $40-49$ & $-0.12^{\star \star}$ & $-0.10^{\star *}$ & $-0.09^{\star *}$ & & $-0.09^{\star \star}$ & $-0.09^{* \star}$ \\
\hline \multicolumn{7}{|l|}{ Age at first marriage (ref: over 26) } \\
\hline Under 22 & & $0.44^{\star *}$ & $0.36^{\star \star}$ & $0.19^{\star *}$ & & $0.22^{\star *}$ \\
\hline $22-26$ & & $0.26^{\star *}$ & $0.23^{\star \star}$ & $0.09 * *$ & & $0.11^{\star *}$ \\
\hline \multicolumn{7}{|l|}{ Residence region (ref: South) } \\
\hline North & & & $-0.19^{* *}$ & $-0.17^{* *}$ & $-0.18^{\star \star}$ & $-0.18^{\star *}$ \\
\hline Centre & & & $-0.18^{\star *}$ & $-0.15^{\star \star}$ & $-0.16^{\star \star}$ & $-0.16^{\star \star}$ \\
\hline \multicolumn{7}{|l|}{ Educational level (ref: low) } \\
\hline High & & & $-0.05^{*}$ & $-0.04^{*}$ & $-0.10^{* *}$ & $-0.03 \dagger$ \\
\hline Middle & & & $-0.07^{* \star}$ & $-0.07^{* *}$ & $-0.08^{\star \star}$ & $-0.05^{\star *}$ \\
\hline \multicolumn{7}{|c|}{ Employment status at first marriage (ref: not employed) } \\
\hline Employed & & & $-0.08^{\star *}$ & $-0.08^{\star *}$ & $-0.11^{\star \star}$ & $-0.08^{\star *}$ \\
\hline \multicolumn{7}{|l|}{ Presence of separated parents (ref: no) } \\
\hline Yes & & & 0.03 & 0.04 & 0.02 & 0.02 \\
\hline \multicolumn{7}{|l|}{ Siblings (ref: 2 or more) } \\
\hline 0 & & & $-0.16^{\star \star}$ & $-0.16^{\star *}$ & $-0.16^{\star \star}$ & $-0.16^{\star *}$ \\
\hline 1 & & & $-0.10^{\star *}$ & $-0.11^{\star *}$ & $-0.11^{\star \star}$ & $-0.10^{\star *}$ \\
\hline \multicolumn{7}{|l|}{ Ceremony of first marriage (ref: Religious) } \\
\hline Civil & & & -0.01 & -0.01 & -0.01 & 0.01 \\
\hline \multicolumn{7}{|c|}{ Number of reproductive years spent in a union } \\
\hline $0-3$ years & & & & $-0.59^{* *}$ & $-0.60^{\star \star}$ & $-0.58^{* *}$ \\
\hline 4-6 years (ref.) & & & & 0.00 & 0.00 & 0.00 \\
\hline $7-9$ years & & & & $0.23^{* *}$ & $0.23^{\star \star}$ & $0.21^{\star *}$ \\
\hline 10 or more years & & & & $0.46^{* *}$ & $0.46^{\star \star}$ & $0.36^{\star \star}$ \\
\hline \multicolumn{7}{|c|}{ Experience of separation and of a second union (ref: no $\ddagger$ ) } \\
\hline $\begin{array}{l}\text { Separation under age } 40 \text {, no second } \\
\text { union in reprod. age }\end{array}$ & $-0.33^{\star \star}$ & $-0.34^{* *}$ & $-0.31^{\star \star}$ & $-0.13^{* *}$ & $-0.09 * *$ & $-0.14^{*}$ \\
\hline $\begin{array}{l}\text { Separation under age } 40 \text {, second union } \\
\text { in reprod. age }(<40)\end{array}$ & $-0.16^{\star \star}$ & $-0.24^{\star *}$ & $-0.15^{\star \star}$ & $-0.11^{*}$ & -0.05 & $-0.10^{*}$ \\
\hline
\end{tabular}

$\ddagger$ This category includes women who underwent separation when they were over the age of 40 $\dagger=p<.10,{ }^{*}=p<.05,{ }^{* *}=p<.01$

When only the age at the time of the interview is controlled for, women undergoing marital separation are shown to have, on average, fewer children than those still in a first marriage at the time of the interview, or women who separated over the age of 40 (Model 1). The number of children among the former group is $15 \%$ ( $\exp (-$ $0.16)=0.85)$ lower than among the latter group or $28 \%(\exp (-0.33)=0.72)$, depending on whether the women entered a second union at a fecund age. If we adjust for differences in the age at first marriage (Model 2), the depressing effect of marital instability on fertility is shown to increase among separated women who repartnered. 
Thus, controlling only for the age at the time of the interview is distorting because it does not take into account the finding that women who repartnered are more likely than those in continuous marriages to have married at younger ages (which has been shown to be positively associated with fertility).

In Model 3, we also controlled for women's socioeconomic and cultural factors. The effect of these additional controls was to bring the fertility differentials back to the levels seen in Model 1, which suggests that separated women (in particular, those who repartnered) are selected for background characteristics that reduce their fertility. In summary, if it were not for the fact that women who separate tend to have certain characteristics which reduce or increase their fertility relative to women who stay in their marriages, the impact of marital disruption on fertility would be reduced to $27 \%$ $(\exp (-0.31)=0.73)$ for women who are separated with no repartnering, and to $14 \%$ (exp($0.15=0.86$ ) for those who repartner, relative to those who remained continuously married. As hypothesised, marital instability thus lowers women's fertility irrespective of their subsequent partnership experience: separated women who did not repartner have lower fertility than those in continuous marriage; while those who repartnered have higher fertility than those who did not enter a new union. But, as hypothesised, the fertility of repartnered women remains lower than that of continuously married women.

Next, we examine what happens if we control for the exposure to the risk of conception (Models 4-6). Theoretically, none of these models is realistic because separated women could not experience the same level of exposure (duration in union) as continuously married women, once both the ages at the start (the age at first marriage) and at the end (the age at the time of the interview) of the life course studied have been established. However, with some caveats, we can assert that these models provide rough information about the role played by exposure in depressing the fertility of women who underwent a marital dissolution. In general, they document that, regardless of the woman's union career, the number of reproductive years spent in a union has a positive and significant effect on the cumulated fertility. More specifically, Model 4, which jointly controls for the woman's age at first marriage and the number of reproductive years spent in a union, shows that the duration has a significant effect in depressing the fertility of women who underwent separation: after controlling for this effect, the fertility of separated women becomes just $10 \%$ and $12 \%$ lower than the fertility of continuously married women, depending on whether they entered a second union at a fecund age. However, it should be stressed that, in this model, separated women are compared with continuously married women, who are necessarily younger than the separated women at the time of the interview. Model 5, which controls for the duration and the woman's age at interview, confirms that the age at first marriage is an important disturbing factor, and that its omission may lead to an underestimation of the depressing effect of marital instability on women's fertility, especially in the case of 
repartnering (see also Model 1). Model 6, which controls for the combined effects of age at marriage, age at the time of the interview, and duration, could not be estimated if the three covariates were exactly measured (at least for women in intact marriages who were under age 44 at the time of the interview). However, the use of categories large enough to permit adequate (but meaningful) comparisons between married and separated women enable us to overcome this problem, and to further speculate on the effect of the time spent in a union. The results are similar to those of Model 4: the loss of exposure negatively influences the fertility of separated women, and, as was assumed, the effect of this loss is stronger for women who did not repartner. Indeed, after controlling for this effect, the negative fertility differentials relative to continuously married women were found to have declined from $27 \%$ to $13 \%$ for women who did not repartner, and from $14 \%$ to $10 \%$ for those who repartnered (see also Model $3)$.

\section{Conclusions}

This paper has investigated the reproductive behaviour of Italian women who underwent a marital dissolution while at fecund ages, using data updated to 2003. Two main issues were explored: the question of what effects certain family life-course factors have on the risk of post-dissolution childbearing, and the question of to what extent marital instability lowers the fertility of women whose first marriages ended, relative to those women who remained continuously married. Given that, in Italy, marital instability is, though rapidly increasing, a relatively recent and still barely socially accepted phenomenon, our main assumption is that the reproductive behaviour of separated women may differ from the behaviour of their counterparts living in countries with a longer experience of the phenomenon. Specifically, we hypothesise that, in such a traditional family context, childbearing following marital disruption has additional psychological costs that encourage cautious reproductive behaviour among separated women. As a consequence, separated women who did repartner could not recapture the fertility lost due to the ending of the first marriage, even though the desire to have shared children with the new partner is a potential path for reaching this result. Thus, on the whole, marital dissolution can be seen as a new factor in fertility reduction.

The analyses showed that the end of the first marriage is not necessarily the end of a woman's reproductive history, even if the risk of a post-dissolution birth is strongly associated with the family events experienced by the woman both before and after the union dissolution. As expected, entering a marriage is a strong predictor of the occurrence of this event. However, contrary to our hypothesis, even cohabitation is greatly associated with the likelihood of post-dissolution childbearing. Thus, even 
cultural environments that are not conducive to marital instability-such as that of Italy - do not discourage separated women from having children outside formal unions. The results concerning the effects of children born during the first marriage on the risk of a post-dissolution birth are less clear. Looking at the coefficient's values, we found that a) our hypothesis of a negative effect of parity was supported, and that b) our hypothesis that separated women prefer longer rather than shorter birth intervals was also supported. However, statistical tests did not confirm these results: the only significant difference found in the risk of a post-dissolution birth was between separated women with no children and separated women with children, so that separated women with at least one child seem to have the same probability of having another child as those with two or more children. Thus, from a statistical point of view, the theory of a linear association between parity and the probability of post-dissolution childbearing is not completely confirmed, and the unique value of a first shared child in a stepfamily (Vikat et al. 1999) may be not completely excluded, even in Italy. In addition, the ages of the children at the time of marital dissolution do not seem to be particularly relevant for the risk of having a subsequent child. As a consequence, Italian separated women do not appear to significantly prefer having a post-dissolution child when the last-born child is somewhat older in order to better distribute over time the (psychological and rearing) costs of having another child.

If we look at the entire life spans of women, we find that separated women produce fewer children than their counterparts who remain in intact marriages, although the size of these fertility differentials depend on women's subsequent repartnering histories. As expected, separated women who did not repartner during their reproductive years have the lowest fertility: their cumulated number of children is, on average, $27 \%$ lower than that of women who were continuously married, and a large part (at least one half) of this gap seems to be explained by the loss of exposure to the risk of pregnancy as a result of the disruption of the first marriage. As assumed, we found that separated women who repartnered at reproductive ages had an intermediate cumulated fertility: their fertility was $14 \%$ lower than that of women in intact marriages. Thus, repartnering makes an important contribution to, but is not sufficient for, recapturing the fertility lost with the dissolution of the first marriage. Therefore, in Italian society, marital instability has been shown to result in an overall loss in fertility. In the future, however, the spread of marital instability may not necessarily lead to a heavy decrease in fertility if the formation of stepfamilies becomes common, and if early repartnering prevails. However, the same results show that residual fertility gaps remain between separated and continuously married women, even after controlling for the total number of years spent in a union. Further analyses that investigate the question of whether separated women are selected for some factors that are not perfectly measured here, or for unobserved characteristics (e.g., lower fecundity, lower fertility 
preferences) associated with the likelihood of having children (see Coppola and Di Cesare 2008) are therefore required.

In summary, empirical analyses show that separated women who repartnered have relatively prudent reproductive behaviours, which suggests that psychological costs may operate in contexts in which marital instability is still relatively uncommon, and is not generally accepted. However, the same analyses indicate that repartnered women may also engage in some non-traditional family behaviours (which are reflected in the relatively high risk of post-dissolution childbearing in informal unions, and the nonlinear effect of the number of previous children on the risk of having a post-dissolution child), and may have a relatively small fertility differential relative to continuously married women. These findings in turn suggest that the psychological costs might have weaker effects than those we assumed.

This study has provided important insights into the fertility behaviour of Italian women who experience the dissolution of their first marriage. However, this research also has a number of shortcomings that should be mentioned.

The analysis of the determinants of post-dissolution childbearing is affected by some data restrictions that do not make it easy to isolate the effect of pre-union children. The few cases of repartnered women with children born in the first marriage did not allow us to test the interactions between parity/ages of the previous children and other relevant covariates of the model (particularly duration since marital disruption). As a consequence, the main effects presented here are not supported by thorough indepth investigations that could have made the results more robust. In addition, because our data do not include complete information about the partners' children, we were unable to assess the potential influence on stepfamily childbearing of various partner parities. Some studies have demonstrated that partners' children influence stepfamily childbearing (Vikat et al. 1999). However, those researchers who have taken into account the children's living arrangements have found that the risk of a woman having a post-dissolution child depends essentially on the number and characteristics of her partner's pre-union children who live in the household (Buber and Prskawetz 2000; Vikat et al. 2004). Because in Italy the children of separated couples usually live with their mothers (that is, the partner's pre-union children do not live in the stepfamily), we may assume that our results mainly represent the effect of pre-union children of women whose partners have no pre-union children living in the stepfamily. Further efforts to supplement the childbearing and the partnership histories with more complete data on both husbands and wives will provide a clearer picture of these effects.

Our analysis of the effects of marital instability on women's cumulated fertility also has some limitations. First, by using a sample of women aged 25-64 whose lifecourse trajectories were truncated by the woman's age at the time of the interview, we may be distorting the effect of marital dissolution on fertility, because we are 
combining cohorts with differing marital and fertility experiences. In particular, the fact that the fertility of divorced women is changing through the birth cohorts (Beaujouan and Solaz 2008; Thomson et al. forthcoming) may have the effect of changing the relationship between marital disruption and fertility. Second, our analytic approach measures the net differentials of cumulated fertility between women in intact marriages and separated women, without breaking them down into the components that are related to fertility in the first marriage, and the components that are related to fertility following the end of the first marriage. As a consequence, we cannot, for example, say why it is that - even after controlling for the time of exposure - the fertility of repartnered women remains lower than that of continuously married women. Does this finding imply that repartnered women experienced lower fertility during their first marriages, and that this is not compensated for by stepfamily fertility; or that a similar level of marriage fertility is not adequately completed by the level of stepfamily fertility? More generally, the analysis presents a synthetic, but still rough, estimate of the effect of marital instability on fertility, without isolating the factors that could contribute to the underlying processes that produce the outcomes, and without testing for the presence of unobserved heterogeneity that can jointly influence two or more of the involved processes. Thus, more complex multi-process models that are capable of taking into account simultaneously fertility, marital disruption, and repartnering should be used. However, the small size of our samples made it difficult to implement these models (it is, for example, hard to estimate the correlation between the heterogeneity components using our sample). Further surveys that include more detailed data and richer samples might be used in future to overcome these problems. 


\section{References}

Anxo, D., Flood, L., Mencarini, L., Pailhé, A., Solaz, A., and Tanturri, M.L. (2007). Time allocation between work and family over the life-cycle: a comparative gender analysis of Italy, France, Sweden and the United States. IZA Discussion Paper (No. 3193).

Beaujouan, E. and Solaz, A. (2008). Childbearing after separation. Do second unions make up for missing births? Evidence from France. Paris: INED (Documents de travail n.155).

Billari, F.C. (2005). Partnership, childbearing and parenting: trends of the 1990s. In: The New Demographic Regime. Population Challenges and Policy Responses. Geneva: United Nations: 63-94.

Blossfeld, H.P. and Rohwer, G. (2002). Techniques of event history modelling. New approaches to causal analysis. London: Lawrence Erlbaum Associates.

Brown, S.L. (2000). Fertility following marital dissolution. The role of cohabitation. Journal of Family Issues 21(4): 501-524. doi:10.1177/019251300021004005.

Buber, I.A. and Prskawetz, A. (2000). Fertility in second union in Austria. Findings from the Austrian FFS. Demographic Research 3(2). doi:10.4054/DemRes. 2000.3.2.

Cameron, A. and Trivedi, P. (1998). Regression Analysis of Count Data. Cambridge University Press.

Clarke, S., Diamond, I., Spicer, K., and Chappell, R. (1993). The relationship between marital break-down and childbearing in England and Wales. In: Bhrolchain M.N. (ed.). New Perspectives on Fertility in Britain. London: HMSO: 123-136.

Cohen, S.B. and Sweet, J.A. (1974). The impact of marital disruption and remarriage on fertility. Journal of Marriage and Family 36: 87-96. doi:10.2307/350998.

Coppola, L. and Di Cesare, M. (2008). How fertility and union stability interact in shaping new family patterns in Italy and Spain. Demographic Research 18(4): 117-144. doi:10.4054/DemRes.2008.18.4.

De Sandre, P., Ongaro, F., Rettaroli, R., and Salvini, S. (1997). Matrimonio e figli: tra rinvio e rinuncia. Bologna: Il Mulino.

De Sandre, P., Ongaro, F., Rettaroli, R., and Salvini, S. (2000). Fertility and Family Surveys in Countries of the ECE Regions. Standard Country Report, Italy. 
United Nations, New York: United Nations Economic Commission for Europe, Economic Studies n.10.

Diamond, I., Clarke, S., and Clarke, P. (1995). The impact of marital breakdown on the quantum and tempo of childbearing in England and Wales. Paper presented at European Population Conference, Milan, September 4-8 1995.

Esping-Andersen, G. (1990). The three worlds of welfare capitalism. Cambridge: Polity Press.

EUROSTAT (2008). Population in Europe 2007: first results. Statistics in focus $81 / 2008$.

Griffith, J.D., Koo, H.P., and Suchindran, C.M. (1985). Childbearing and family in remarriage. Demography 22: 73-88. doi:10.2307/2060987.

Henz, U. and Thomson, E, (2005). Union stability and stepfamily fertility in Austria, Finland, France \& West Germany. European Journal of Population 21(1): 3-29. doi: 10.1007/s10680-004-7267-4.

ISTAT (2004). Separazioni, divorzi e affidamento dei minori, anno 2002, Centro di Informazione Statistica - Servizio Giustizia, Roma: ISTAT.

ISTAT (2007). Separazioni e divorzi in Italia, anno 2005. Centro di Informazione Statistica - Servizio Giustizia, Roma: ISTAT.

Jansen, M., Wijckmans, B., and Bavel, J.V. (2008). The influence of divorce on the cumulated fertility of men and women across Europe. Paper presented at the European Population Conference 2008, Barcelona, Spain, July 9-12 2008.

Jefferies, J., Berrington, A., and Diamond, I. (2000). Childbearing following marital dissolution in Britain. European Journal of Population 16: 193-210. doi:10.1023/A:1026529300659.

Kertzer, D.K., White, M., Bernardi, L., and Gabrielli, G. (2009). Italy's path to very low fertility: the adequacy of economic and Second Demographic Transition theories. European Journal of Population 25 (1): 89-115. doi:10.1007/s10680008-9159-5.

Lauriat, P. (1969). The effect of marital dissolution on fertility. Journal of Marriage and the Family 31: 484-493. doi:10.2307/349770.

Leone, T. and Hinde, A. (2007). Fertility and union dissolution in Brazil: an example of multi-process modelling using the Demographic and Health Survey calendar data. Demographic Research 17(7): 157-180. doi:10.4054/DemRes.2007.17.7. 
Leridon, H. (1990). Extra-marital cohabitation and fertility. Population Studies 44(3): 469-487. doi:10.1080/0032472031000144856.

Lesthaeghe, R. and Moors, G. (1994). Expliquer la diversité des formes familiales et domestiques: théories économiques et dimensions culturelles. Population 49(6): 1503-1525. doi:10.2307/1534020.

Lillard, L.A., Panis, C.W.A., and Upchurch, D.M. (1994). Interdependencies over the life course: women's fertility, marital, and educational experiences. Santa Monica, CA: The Rand Corporation, Labor and Population Program (Working Paper 94-17).

Meggiolaro, S. and Ongaro, F. (2008). Repartnering after marital dissolution: does context play a role? Demographic Research 19(57): 1913-1934. doi:10.4054/DemRes.2008.19.57.

Mencarini, L. and Tanturri, M.L. (2009). Fathers' involvement in daily childcare activities in Italy: does a work-family reconciliation issue exist? Centre for Household, Income, Labour and Demographic Economics (Working Paper 22).

Pinnelli, A., De Rose, A., Di Giulio, P., and Rosina, A. (2002). Interrelationships between partnership and fertility behaviour. In: Macura, M. and Beets, G. (eds.). Dynamics of Fertility and Partnership in Europe. Insights and Lessons from Comparative Research. Vol I. New York/Geneva: United Nations: 77-98.

Rindfuss, R.R. and Bumpass, L.L. (1977). Fertility during marital disruption. Journal of Marriage and the Family 39: 471-486. doi:10.2307/350906.

Rosina, A. and Fraboni, R. (2004). Is marriage losing its centrality in Italy? Demographic Research 11(6): 149-172. doi:10.4054/DemRes.2004.11.6.

Rubin, D.B. (1987). Multiple Imputation for Non-Response in Surveys. New York: John Wiley.

Smith Koslowski, A. (2008). Who Cares? European Fathers and the Time spend looking after their Children. UPTAP Research Findings.

Thomson, E. (1997). Her, his and their children: influences on couple childbearing decisions. Center for Demography and Ecology, University of WisconsinMadison (NSFH Working Paper 76).

Thomson, E. and Li, J-C.A. (2002). Her, his and their children: childbearing intentions and births in stepfamilies. Center for Demography and Ecology, University of Wisconsin-Madison (NSFH Working Paper 89). 
Thomson, E., Hoem, J.M., Vikat, A., Buber, I., Prskawetz, A., Toulemon, L., Henz, U., Godecker, A.L., and Kantorova, V. (2002). Childbearing in stepfamilies: whose parity counts? In: Klijzing, E. and Corijn, M. (eds.). Fertility and Partnership in Europe: Findings and Lessons from Comparative Research. Vol. II, New York/Geneva: United Nations: 87-99.

Thomson, E., Winkler-Dworak, M., Spielauer, M., and Prskawetz, A. (forthcoming). Union instability as an engine of fertility? A micro-simulation model for France. Demography.

Thornton A. (1978). Marital dissolution, remarriage, and childbearing. Demography 15(3): 361-380. doi:10.2307/2060656.

Vignoli, D. and Ferro, I. (2009). Rising marital disruption in Italy and its correlates. Demographic Research 20(4): 11-36. doi:10.4054/DemRes.2009.20.4.

Vikat, A., Thomson, E., and Hoem, J.M. (1999). Stepfamily fertility in contemporary Sweden: the impact of childbearing before the current union. Population Studies 53: 211-225. doi:10.1080/00324720308082.

Vikat, A., Thomson, E., and Prskawetz, A. (2004). Childrearing responsibility and stepfamily fertility in Finland and Austria. European Journal of Population 20: 1-21. doi:10.1023/B:EUJP.0000014536.56286.41.

Wineberg, H. (1988). Fertility of women married once or more than once. Sociology and Social Research 72: 260-266.

Wineberg, H. (1990). Childbearing after remarriage. Journal of Marriage and the Family 52: 31-38. doi:10.2307/352835.

Yamaguchi, K. (1991). Event History Analysis. Sage Applied Social Research Methods Series, volume 28, Thousand Oaks, CA: Sage. 
Meggiolaro \& Ongaro: The implications of marital instability for a woman's fertility 